\title{
Seasonal Difference of the Deep Currents in the Luzon Strait during October 2008-January 2009 and July-August 2009
}

\author{
Yaochu Yuan 1*, Weibing Guan'1, Chenghao Yang1, Yu-Heng Tseng², Huiqun Wang1 \\ ${ }^{1}$ State Key Laboratory of Satellite Ocean Environment Dynamics, Second Institute of Oceanography, Ministry of Natural \\ Resources, Hangzhou, China \\ ${ }^{2}$ Institute of Oceanography, National Taiwan University, Taiwan \\ Email: *yuanyc6@163.com, *yuanyc2@sio.org.cn
}

How to cite this paper: Yuan, Y.C., Guan, W.B., Yang, C.H., Tseng, Y.-H. and Wang, H.Q. (2019) Seasonal Difference of the Deep Currents in the Luzon Strait during October 2008-January 2009 and July-August 2009. Atmospheric and Climate Sciences, 9, 284-297. https://doi.org/10.4236/acs.2019.93020

Received: March 28, 2019

Accepted: May 27, 2019

Published: May 30, 2019

\section{Copyright $\odot 2019$ by author(s) and} Scientific Research Publishing Inc. This work is licensed under the Creative Commons Attribution International License (CC BY 4.0).

http://creativecommons.org/licenses/by/4.0/

\section{(c) (i) Open Access}

\begin{abstract}
Based on direct current measurements from two separated cruises in October 2008-January 2009 and July-August 2009, we obtained a valuable deep current observation of the Luzon Strait (LS). Rectified wavelet power spectra analysis (RWPSA) and the geostrophic current calculation are used to study the deep current. We find that the deep current differs in different seasons. The current is strongest in autumn (October-November) and weaker in summer (July-August) and in winter (December-January). The cyclonic and anti-cyclonic meander with different subtidal current directions plays an important role in the seasonal difference of the deep current in the LS. The observed seasonal difference of the deep current in the LS is connected with the deep current observed at the western boundary of the northern Philippine Basin and is also linked with the overflow near the central Bashi Channel and Luzon Trough. The RWPSA of the long observation suggests the dominant periods of $8 \mathrm{~d}, 19 \mathrm{~d}$ in the deep current. The dynamical cause of the resulting velocity distribution at 1850 and $1760 \mathrm{~m}$ is the pressure field and bottom topography steering. The observed deep current agrees well with the geostrophic current calculation.
\end{abstract}

\section{Keywords}

Luzon Strait, Long Measurement of Deep Currents, Seasonal Difference, Rectified Wavelet Power Spectra Analysis, Dynamical Cause of Resulting Deep Current Distribution

\section{Introduction}

The water exchange between the Pacific water and the South China Sea (SCS) 
through the Luzon Strait (LS) plays a very important role in the circulation of the SCS. Overall, the exchange can be categorized into three different layers, namely, the upper layer above $400 \mathrm{~m}$, the middle layer between 500 and $1200 \mathrm{~m}$, and the deep layer. In the upper layer above $400 \mathrm{~m}$ in the LS, a considerable number of studies have discussed the westward intrusion of the Kuroshio into the SCS through the LS (e.g., [1] [2] [3] [4]). In particular, many studies have emphasized the dynamical cause of the westward Kuroshio intrusion (e.g., [2] [3] [5]-[10]). They only studied the circulation in the upper $1000 \mathrm{~m}$ of the LS during the summer of 2009 [2]. This summer Kuroshio intrusion resulted from the weaker upstream Kuroshio transport due to inertial effects (El Niño initiating period) and was associated with weak volume transport across the LS (2.15 $\mathrm{Sv}$ westward; $1 \mathrm{~Sv}=10^{6} \mathrm{~m}^{3} \cdot \mathrm{s}^{-1}$ ) [2]. In the middle layer between $500 \mathrm{~m}$ and 1200 $\mathrm{m}$ (or $1500 \mathrm{~m}$ ), the SCS water flows out to the Pacific. It was suggested that the net eastward volume transport was about $2.4 \mathrm{~Sv}$ in this middle layer [11]. Only a few observations can be found regarding the deep water in the LS. The deep current was first observed by direct mean current velocity measurements in the Bashi Channel by [12]. They pointed out that the deep layer volume transport was about $1.2 \mathrm{~Sv}$ toward the west in the Bashi Channel. An overall transport of $2.5 \mathrm{~Sv}$ below $1500 \mathrm{~m}$ was estimated using hydrographic data [13]. Based on the results of numerical simulation [14], they estimated the annual mean deep-water $(1500-2500 \mathrm{~m})$ overflow transport of around $1.7 \mathrm{~Sv}$ and its direction was westward.

Most previous current measurements in the LS used the shorter observational time periods (less than one month), except [15] [16]. For example, a field experiment was conducted in the LS from October 4 to 16, 2005 [17]. They showed that the net westward volume transport in the deep layer $(>1500 \mathrm{~m})$ of the LS reaches $2 \mathrm{~Sv}$. However, their observational periods of $13 \mathrm{~d}$ were short to fully explain the characteristics of the deep current in the LS or its possible seasonality.

In terms of the analysis, the rectified wavelet power spectra analysis (RWPSA) was first proposed by [18], which divides the spectrum by the associated scale so that the spectral peaks of the same magnitude are similar in size [18]. A physically consistent definition of energy for the wavelet power spectrum is also suggested, based on the square of the transformation coefficient divided by its associated scale. The adjusted wavelet power spectrum results in a substantial improvement in the spectral estimate, allowing a further detailed comparison of spectral peaks across scales.

Based on the ADCP deployed at the mooring station $\mathrm{N} 2\left(20^{\circ} 40.441^{\prime} \mathrm{N}\right.$, $120^{\circ} 38.324^{\prime} \mathrm{E}$ ) of the LS in depths of $50-300 \mathrm{~m}$ between July 7, 2009 and April 10, 2011, and the TDs at around 340 and $365 \mathrm{~m}$ between July 9, 2009 and July 9, 2011, a longer period variation of the Kuroshio into the LS was investigated [16]. Their observations suggested long-period variation in the upper layer of the LS and identified two types of dominant periods. The first type had the dominant period of $112 \mathrm{~d}$ with the strongest power spectral density and was found throughout the upper $300 \mathrm{~m}$. The occurrence of the most dominant period of 
$112 \mathrm{~d}$ in the upper $300 \mathrm{~m}$ is directly related to the clockwise meandering of the Kuroshio into the LS, which is caused by westward propagating stronger anticyclonic eddies from the interior ocean due to the interaction of Rossby eddies with the Kuroshio [16]. The second type of dominant period, for example the period of $40 \mathrm{~d}$, related closely to the anticlockwise meandering of the Kuroshio [16]. However, no deep current observation was addressed.

Based on a long mooring observation in the deep Bashi Channel and Luzon Trough, the deep-water overflows are estimated to be $0.83 \pm 0.46 \mathrm{~Sv}$ and $0.88 \pm$ $0.77 \mathrm{~Sv}$ at the Bashi Channel and the Luzon Trough, respectively [15]. Significant intraseasonal and seasonal variations were also identified, with dominant timescales ranging between $20 \mathrm{~d}$ and $60 \mathrm{~d}$, and approximately $100 \mathrm{~d}$, respectively. The maximum strength is observed in March-May. Deep-water eddies are believed to play a role in this intraseasonal variation [15]. However, only the transport is estimated without any detailed monthly averaged current velocity. In addition, the location of this mooring station was different from the N2 mooring station [2].

The present study represents the first investigation of the deep current in the LS over a long period (a total of $122 \mathrm{~d}$ from two separated cruises) using a direct measurement. This long dataset is very valuable and unique, because it reveals the existence of seasonal difference of the deep current in the LS. The RWPSA also suggests that the dominant periods of variability are similar to some dominant periods observed in the upper ocean. Section 2 presents the characteristics of deep currents in the LS during the two cruises. Section 3 analyzes the dominant period for the time series using RWPSA. The direct measurement is also compared with the geostrophic current calculation to confirm the dynamical processes in Section 4. Finally, the conclusion is given in Section 5.

\section{The Characteristics of Deep Currents in the Luzon Strait during the Two Cruises}

\subsection{Observed Deep Currents at Mooring Stations N2-1 and N2-2 in the Two Cruises}

Figure 1 shows the location of the mooring stations N2-1 and N2-2 within the rectangular computed region and the bottom topography. There were two cruises between October 2008 and August 2009. Since the actual deployed locations differ slightly between these two cruises, we denote the individual mooring stations as N2-1 and N2-2. During the first cruise, the mooring station N2-1 was located at $20^{\circ} 38.872^{\prime} \mathrm{N}, 120^{\circ} 38.758^{\prime} \mathrm{E}$ in the $\mathrm{LS}$, which was located very close to the mooring station $\mathrm{N} 2$ at $20^{\circ} 40.441^{\prime} \mathrm{N}, 120^{\circ} 38.324^{\prime} \mathrm{E}$ (see [2]). The water depth at mooring station N2-1 was about $2150 \mathrm{~m}$ (see Figure 1). The ADCP moored system at N2-1 was deployed on October 16, 2008 onboard the R/V Dongfang Hong-2 and was recovered on July 5, 2009 onboard the same vessel. However, valid data were taken only from October 16, 2008 to January 8, 2009, i.e., for less than three months. The Aanderaa RCM9 MK II Current Meter (RCM9 thereafter) was set at the average depth of about $1850 \mathrm{~m}$. 


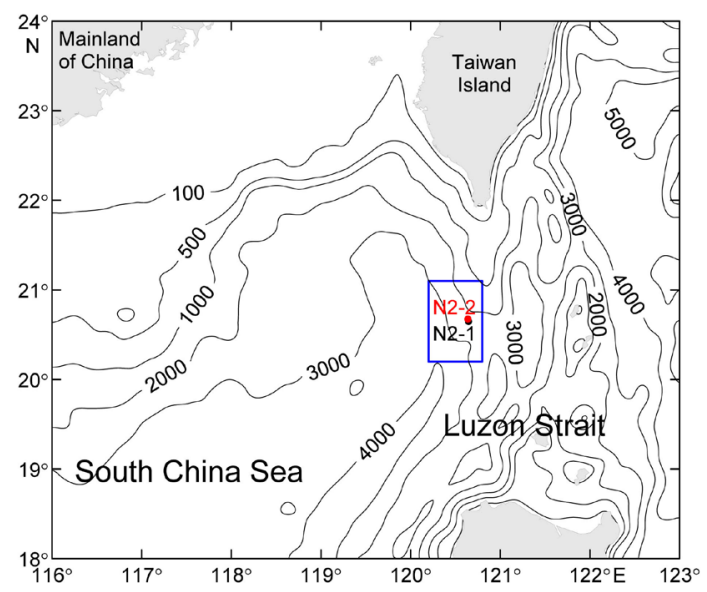

Figure 1. Location of the mooring stations N2-1 $\left(20^{\circ} 38.872^{\prime} \mathrm{N}, 120^{\circ} 38.758^{\prime} \mathrm{E}\right)$ and N2-2 $\left(20^{\circ} 40.441^{\prime} \mathrm{N}, 120^{\circ} 38.324^{\prime} \mathrm{E}\right)$ within the rectangular hydrographical data region $\left(120^{\circ} 20^{\prime} \mathrm{E}\right.$ $\left.-120^{\circ} 40^{\prime} \mathrm{E}, 20^{\circ} 30^{\prime} \mathrm{N}-20^{\circ} 45^{\prime} \mathrm{N}\right)$. The bottom topography of the Luzon Strait and adjacent areas are also shown.

During the second cruise, the mooring station N2-2 was located at $20^{\circ} 40.441^{\prime} \mathrm{N}$, $120^{\circ} 38.324^{\prime} \mathrm{E}$, which is the same as the location of the mooring station N2 in [2], and very close to the N2-1 location in the first cruise (water depth is also about $2150 \mathrm{~m}$ ). Since the RCM9 with temperature pick-up was set at an average depth of about $1760 \mathrm{~m}$, we named this N2-2 to differentiate from the N2 and N2-1 stations. The moored system at N2-2 was deployed on July 7, 2009 onboard the R/V Zhongda-31 and was recovered on September 20, 2011 onboard the same vessel ([2] for further details about this station). The RCM9 valid data was taken only from July 7 to August 12, 2009, i.e., 37 days. The hydrographic data were also obtained from July 4 to 11, 2009, see the observational setting [2] for further details. Based on that hydrographic data [2], only the circulation in the upper $1000 \mathrm{~m}$ of the LS was emphasized in [2], while this study emphasizes on the deep current.

\subsection{Seasonal Difference and Characteristics of the Observed Deep Currents in the First and Second Cruises}

During the first cruise, the observed velocity vectors were sampled at a time interval of 20 min. Figure 2(a) shows the progressive vector diagrams of the observed daily subtidal currents at the mooring station N2-1 (1850-m depth) after the removal of the tidal signals, such as at $12 \mathrm{~h}$ and $24 \mathrm{~h}$, from the observed current with the 40-h Chebyshev type-II lowpass filter. The subtidal current velocity was mostly northward from October 16 to 22, 2008 and northwestward or westward from October 22 to December 10, 2008. However, after December 11, 2008, the direction of the subtidal current varied significantly. From December 12 to 21, the subtidal current direction exhibited a cyclonic variance, and then it changed to an anti-cyclonic variance from December 22 to 29, 2008. After December 30,2008 , the cyclonic variance began again, with a 4-d cyclonic eddy period. The monthly averaged subtidal current velocities from October 2008 to 


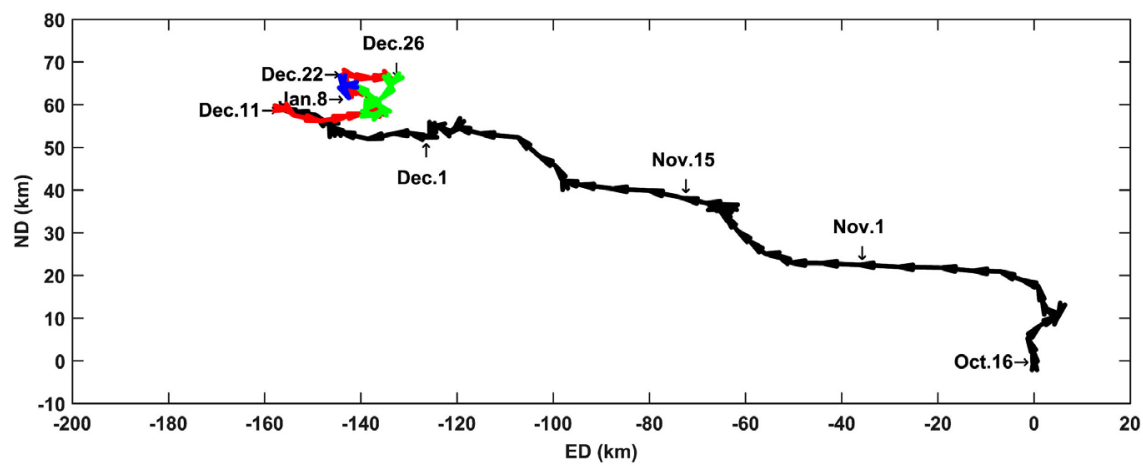

(a)

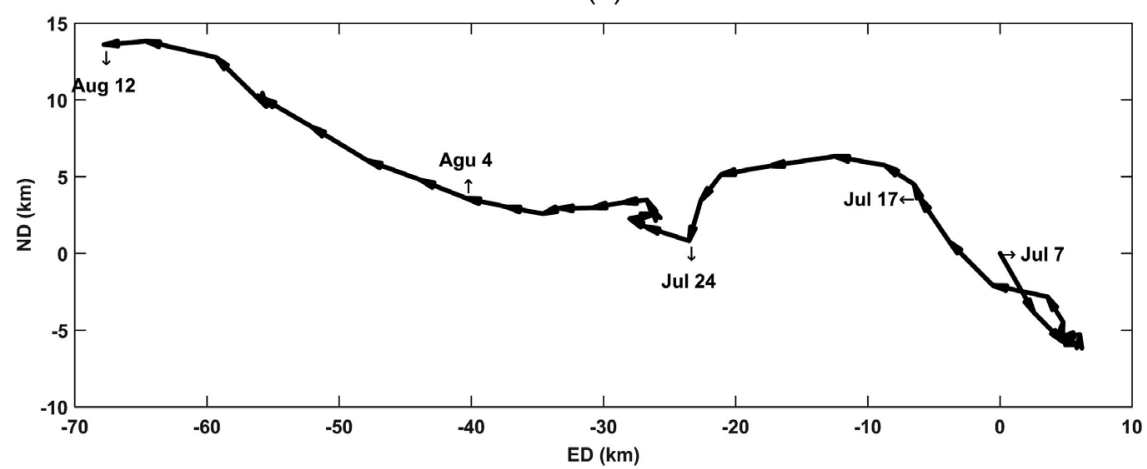

(b)

Figure 2. (a) Progressive vector diagrams of observed daily subtidal currents (tidal signal removed from the observed current using the 40-h Chebyshev type II lowpass filter) in the mooring station N2-1 at the depth of 1850 m (Oct 16-Dec 10: black, Dec 11-Dec 26: red, Dec 26-Jan 5: green, Jan 5-Jan 8: blue); (b) Same as (a) but at the depth of $1760 \mathrm{~m}$ for the mooring station N2-2 from July 7, 2009 to August 12, 2009 (ED: Eastern distance; ND: Northern distance).

January 2009 are $(u, v)=(-2.8,1.6),(-3.5,1.2),(-0.4,0.2)$, and $(-0.9,0.7)$ (unit: $\mathrm{cm} / \mathrm{s}$ ), during 15 days in October, all of November, December, and 8 days in January, respectively. The corresponding maximum values of the subtidal current velocity were $(\mathrm{Vmax}, \theta)=\left(10.2,271^{\circ}\right),\left(9.2,277^{\circ}\right),\left(7.0,286^{\circ}\right)$, and $(9.9$, $270^{\circ}$ ) (unit: $\mathrm{cm} / \mathrm{s}$, in the clockwise direction from the north), respectively. In general, they were all westward. During the entire observation period, the averaged subtidal current velocity was $(u, v)=(-2.0,0.9)$ (unit: $\mathrm{cm} / \mathrm{s})$, which was northwestward. This suggested an overall tendency of the Pacific water intrusion northwestward into the SCS at 1850-m depth through the LS during the observation period of October 16, 2008 to January 8, 2009.

During the second cruise, the observed velocity vectors are sampled at a time interval of $30 \mathrm{~min}$. The observed daily subtidal currents at the mooring station N2-2 (1760-m depth) are shown in Figure 2(b). The averaged subtidal current velocity was $(u, v)=(-2.2,0.4)$ from July 7 to August 12 . From these results, the subtidal deep current velocity suggested an evident seasonal difference, with the strongest current occurring in the autumn (October and November), and successively weaker currents in summer (July and August) and winter (December and January). In general, there is an overall tendency of the Pacific water intru- 
sion northwestward into the SCS in the deep layer through the LS. From the above, the cyclonic and anti-cyclonic meander with different subtidal current directions play an important role in the seasonality of the deep current in the LS (Figure 2). For example, the weakest current occurred in winter (December and January). This is because the direction of the subtidal current varied significantly in winter, which showed many cyclonic and anti-cyclonic variances resulting from eddies after December 12, 2008. The strongest current occurred in autumn (October and November). The direction of subtidal current velocity was mostly northward from October 16 to 22, 2008 and northwestward or westward from October 22 to November 30. In general, the radius of curvature of the cyclonic variance or anti-cyclonic variance in the subtidal current direction is largest in autumn. Thus, the subtidal current is strongest in autumn.

The seasonal difference of the deep current in the LS may be connected with the deep current observed at the western boundary (DCWB) of the northern Philippine Basin [19] and the deep overflow near the central Bashi Channel and Luzon Trough [15]. It was found that a similar seasonal variation in the DCWB in the northern Philippine Basin [19]. They pointed out that the DCWB reverses its direction in April, with a southward flow $(-2.4 \mathrm{~cm} / \mathrm{s})$ in summer/autumn and a northward flow $(1.7 \mathrm{~cm} / \mathrm{s})$ in winter/spring. It is clear that the strongest current observed by them also occurred in autumn and summer, similar to the strongest deep current observed in the LS in this study. The DCWB then weakened after winter. Both deep currents have very similar orders of magnitude (2 $\mathrm{cm} / \mathrm{s}$ ), suggesting the observed current velocities in the DCWB may be connected to the deep current observed here.

The seasonal difference of the deep current in the LS is also consistent with the deep overflow observation near the central Bashi Channel and Luzon Trough [15]. They pointed out that on a seasonal timescale, the deep-water overflow intensifies in late fall (October-December) and weakens in spring (March-May). Deep-water eddies are believed to play a role in this intraseasonal variation [15]. This suggests that the seasonal difference of the deep current may be a robust feature in the LS and DCWB.

\section{Estimation of the Dominant Period Variations for the Deep Currents Time Series Data in Luzon Strait Using RWPSA}

The RWPSA can effectively correct the distorted wavelet spectra in the standard wavelet analysis [18]. Here, we use the RWPSA to estimate the dominant periods for the zonal velocity $\mathrm{U}$ and the meridional velocity $\mathrm{V}$ at $1850-\mathrm{m}$ depth, as their causes are also investigated. The daily mean data was derived by removing the tidal signal and applying the low pass filter (see [16] for details).

\subsection{Zonal Velocity U Time Series Data}

Figure 3(a) shows the RWPSA (top left) and its associated time-averaged power spectra (bottom) for the zonal velocity at $1850 \mathrm{~m}$. The power spectra are also 

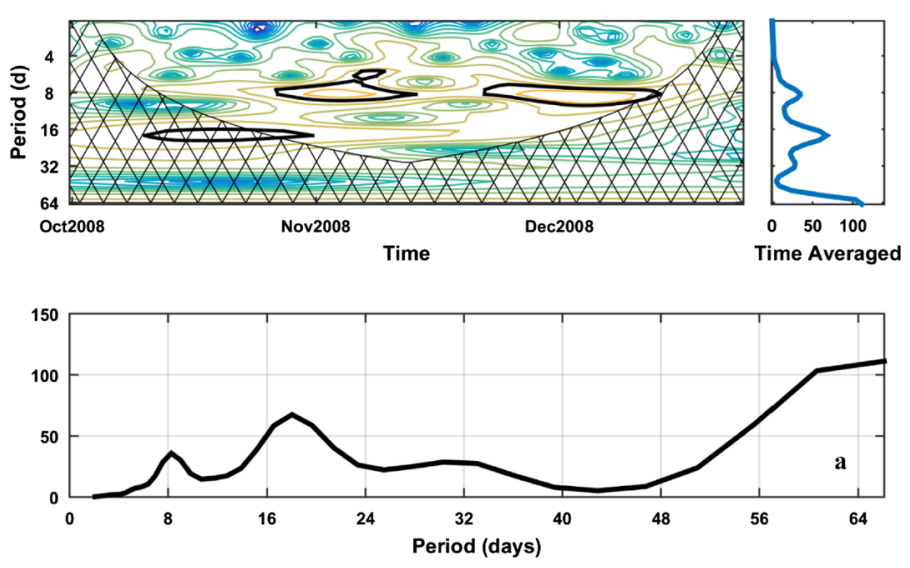

(a)
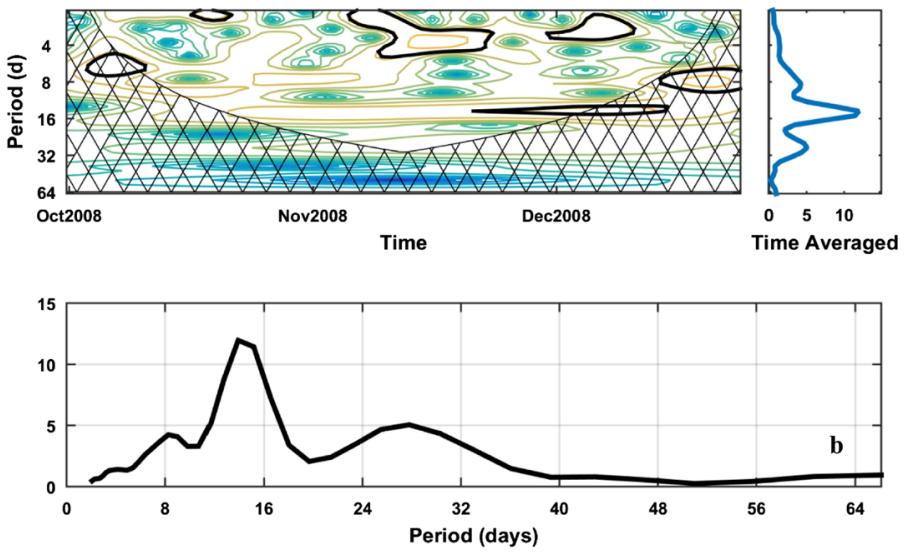

(b)

Figure 3. (a) Top row: rectified wavelet power spectra (left column) and time-averaged rectified wavelet power spectra in base-2 logarithm (right column) for the westward velocity component $\mathrm{U}$ time series at $1850 \mathrm{~m}$ from the observational current velocity at mooring station N2. Red and blue contours indicate high and low wavelet power spectrum values, respectively. The regions of greater than $95 \%$ confidence are shown with thick black contours. Cross-hatched regions indicate the "cone of influence", where edge effects become important. Bottom row: time-averaged rectified wavelet power spectra for the western velocity component $U$ time series at $1850 \mathrm{~m}$; (b) Same as (a) for northern velocity component $\mathrm{V}$ time series.

shown in the top right ( $\log 2$ base). Two dominant periods are found in our study. 1) A period of approximately $8 \mathrm{~d}$ was found with the dimensionless PSD magnitude $\sim 35$. This period can also be found for the zonal velocity at the almost same location in the LS between depths of 50 and $200 \mathrm{~m}$ [16]. They pointed out that the maximum PSD decreases with deepening depths [16]. 2) A period of approximately $19 \mathrm{~d}$ was found with the dimensionless PSD magnitude $\sim 67$. This is also consistent with the anticlockwise and clockwise rotary spectra components in the LS in the upper ocean above 300-m depth [16].

The 8-d period seems to be consistent with the variation observed in the upper $300 \mathrm{~m}$. They suggested that the 8-d period in the upper ocean of the LS is related to both the clockwise and anticlockwise meanderings of the Kuroshio [16]. This similarity and connection requires further analysis. 


\subsection{Meridional Velocity V Time Series Data}

Figure 3(b) shows the same RWPSA and power spectra as Figure 2(a) but for the meridional velocity $\mathrm{V}$ at $1850 \mathrm{~m}$. Three dominant periods are identified. 1) Similar to the zonal velocity $\mathrm{U}$, the period of $8 \mathrm{~d}$ is prevalent with the dimensionless PSD magnitude $\sim 4$, which is much weaker than the zonal velocity. The same period can be identified for the meridional velocity between 50 - and $200-\mathrm{m}$ depths [16]. 2) A period of approximately $14 \mathrm{~d}$ has been found with the dimensionless PSD magnitude $\sim 12$. This is the fortnightly spring-neap tidal period that has been previously reported in the LS (e.g., [1] [16]). 3) The period of approximately $28 \mathrm{~d}$ with the dimensionless PSD magnitude $\sim 5$ is the solid Earth tide that has been reported previously in the LS [16].

\section{Geostrophic Current Calculation}

Based on the hydrographic data obtained from July 4 to 11, 2009 [2] during the second cruise in the LS, the velocity vectors of the deep currents at 1850 and $1760 \mathrm{~m}$ are computed by the dynamical method from [20]. We assume the deep currents are geostrophic so that the equations of motion are written as follows:

$$
\begin{aligned}
& f v=\frac{1}{\rho_{0}} \frac{\partial p}{\partial x} \\
& f u=-\frac{1}{\rho_{0}} \frac{\partial p}{\partial y}
\end{aligned}
$$

The hydrostatic equations are

$$
p=\rho_{0} g \zeta-g \int_{0}^{z}\left(\rho-\rho_{0}\right) \mathrm{d} z
$$

In Equations (1)-(3), $u$ and $v$ are the eastward and northward velocity components, respectively. A constant reference density $\rho_{0}=1032.5 \mathrm{~kg} / \mathrm{m}^{3}, \rho$ and $p$ are the density and pressure anomalies, respectively, Coriolis parameter $f=5.0 \times 10^{-5} \mathrm{~s}^{-1}, \zeta$ is the sea surface elevation, and the other notations are standard. According to the dynamical method from [20],

$$
\zeta=-\frac{1}{\rho_{0}} \int_{-H}^{0}\left(\rho-\rho_{0}\right) \mathrm{d} z
$$

where $H$ is accepted as a reference level, i.e., $H=2400 \mathrm{~m}$, which is the deepest sill in the Bashi Channel [13]. Combining Equations (3) and (4), we can derive the following equation:

$$
p=-g \int_{-H}^{z}\left(\rho-\rho_{0}\right) \mathrm{d} z
$$

From the hydrographic data obtained during July 4 to 11, 2009 [2] i.e., the hydrographic data at 7 observation stations (A1-A5, B4-B5) in the LS (see [2], Figure 4(a) and Figure 4(c)), where the water depths are greater than $2400 \mathrm{~m}$, the pressure anomalies from $2400 \mathrm{~m}$ to 1850 and $1760 \mathrm{~m}$ are calculated at those 7 observation stations according to Equation (5). Then, the pressure anomalies at those 7 stations are mapped onto the grid points in the computed region $\left(120^{\circ} 20^{\prime} \mathrm{N}-120^{\circ} 40^{\prime} \mathrm{E}, 20^{\circ} 30^{\prime} \mathrm{N}-20^{\circ} 45^{\prime} \mathrm{N}\right)$ using a local polynomial method and the resulted valid pressure anomalies are shown in Figure 4(a) and Figure 4(c). 


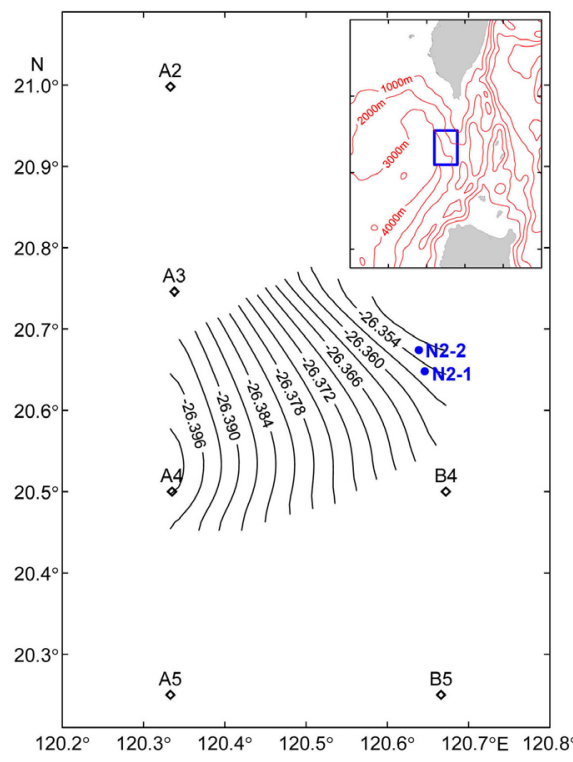

(a)

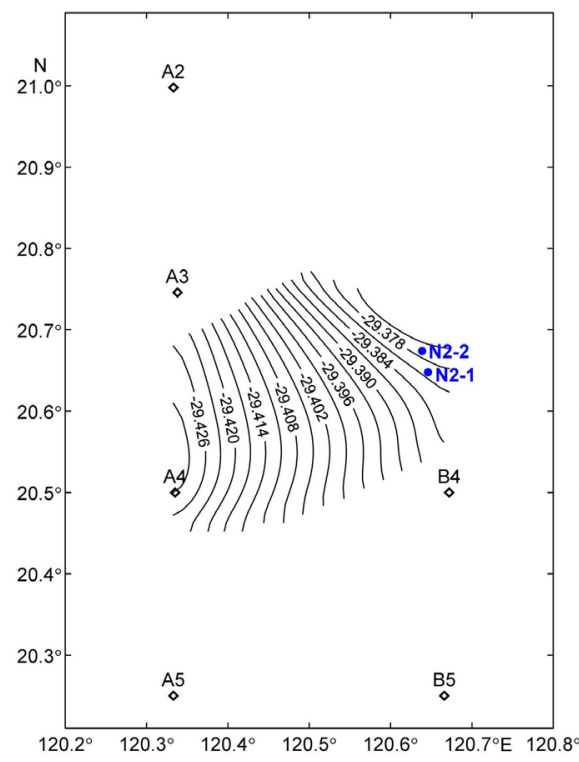

(c)

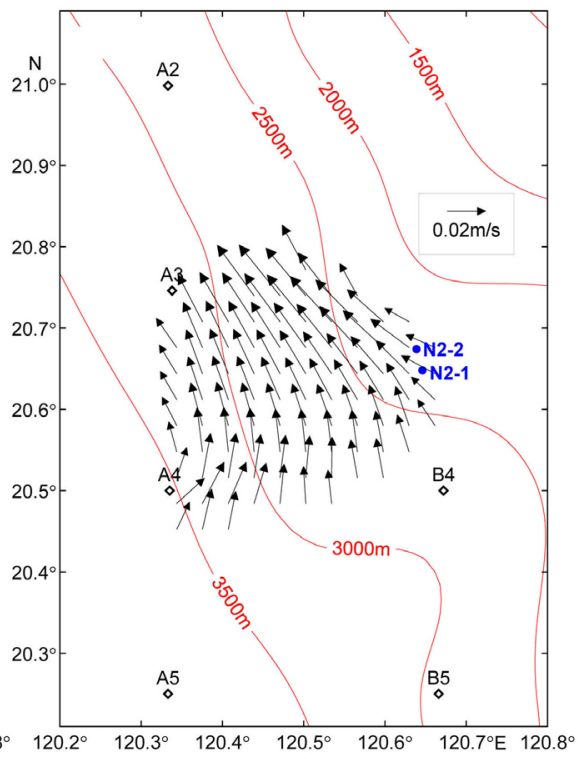

(b)

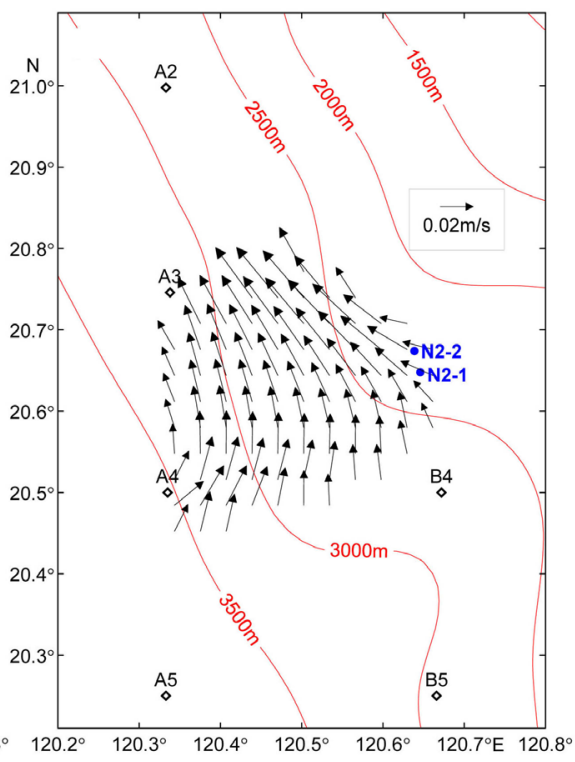

(d)

Figure 4. (a) The pressure anomaly $(\mathrm{kPa})$ distribution and (b) velocity vector $(\mathrm{cm} / \mathrm{s})$ at $1850 \mathrm{~m}$ in the Luzon Strait in July 2009. (c) and (d) are the same as (a) and (b), respectively, but at $1760 \mathrm{~m}$. Red lines: the water depths at isobaths. The reference level is based on $\mathrm{H}=2400$.

From Equations (1), (2), and (5), we can compute the pressure anomalies and, thus, the velocity vectors at 1850 and $1760 \mathrm{~m}$ in the LS in July 2009 (see Figures 4(a)-(d)). Figure 4 shows that the current velocity vectors at 1850 and $1760 \mathrm{~m}$ in the computed region $\left(120^{\circ} 20^{\prime} \mathrm{E}-120^{\circ} 40^{\prime} \mathrm{E}, 20^{\circ} 30^{\prime} \mathrm{N}-20^{\circ} 45^{\prime} \mathrm{N}\right)$ flow nearly northward at about $20^{\circ} 30^{\prime} \mathrm{N}$ and then turn counterclockwise, flowing northwestward in the area $20^{\circ} 35^{\prime} \mathrm{N}$ to $20^{\circ} 45^{\prime} \mathrm{N}$. In other words, the current velocity vectors flow nearly along the isobaths. This is because the ocean currents are expected to flow along the planetary potential vorticity $\mathrm{f} / \mathrm{H}$ contours. For our 
computed region, we assume f-plane, with the currents expected to flow nearly along the isobaths. For example, the current velocity vectors flow nearly along the 3000-m isobaths toward the SCS. Thus, one of dynamical causes of the resulting subtidal velocity distribution at 1850 and $1760 \mathrm{~m}$ is nearly the bottom topography effect.

Now, we consider using the reference level $\mathrm{H}=2150 \mathrm{~m}$, i.e., the water depth at two stations N1-1 and N1-2. Figure 5 shows that the current velocity vectors at 1850 and $1760 \mathrm{~m}$ in the computed region $\left(120^{\circ} 20^{\prime} \mathrm{E}-120^{\circ} 40^{\prime} \mathrm{E}, 20^{\circ} 30^{\prime} \mathrm{N}-20^{\circ} 45^{\prime} \mathrm{N}\right)$

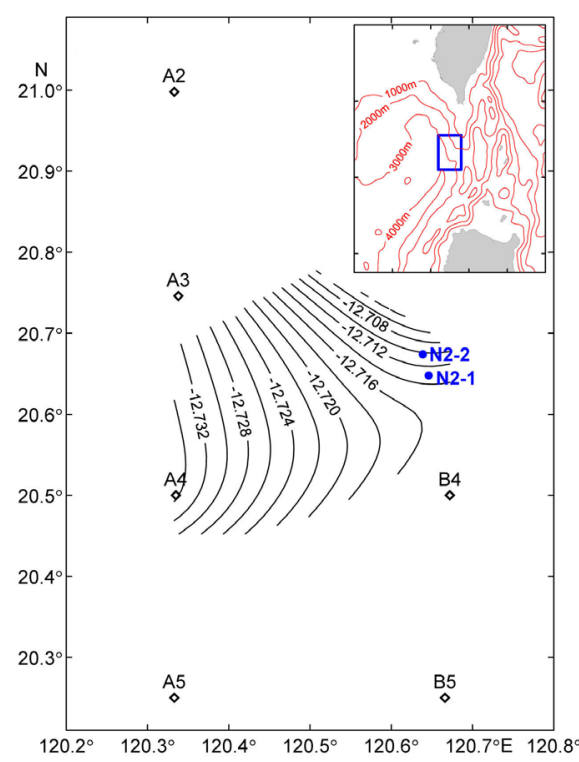

(a)

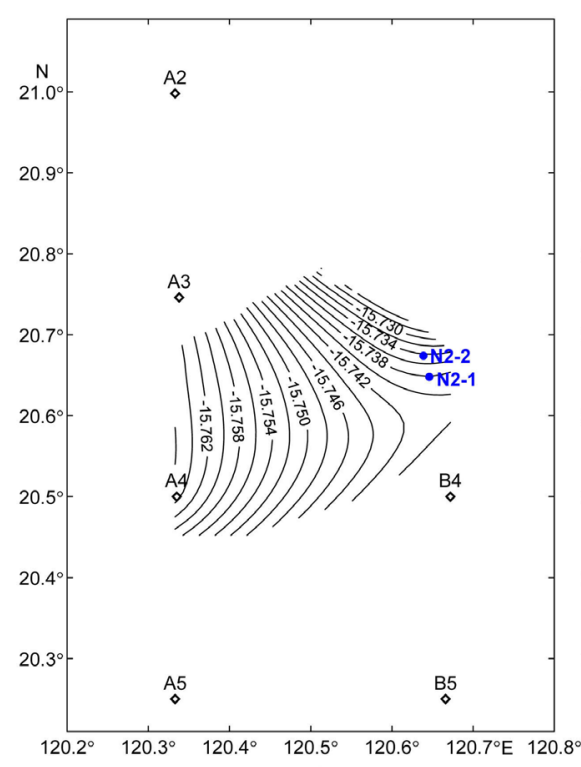

(c)

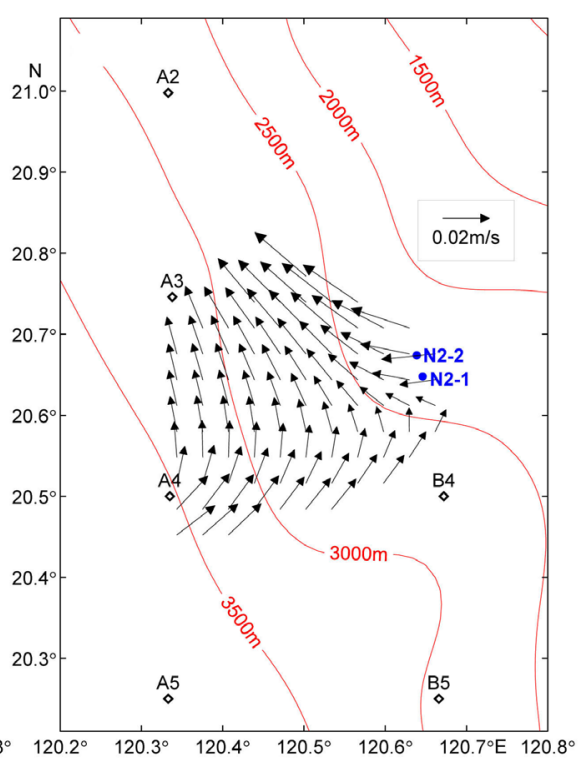

(b)

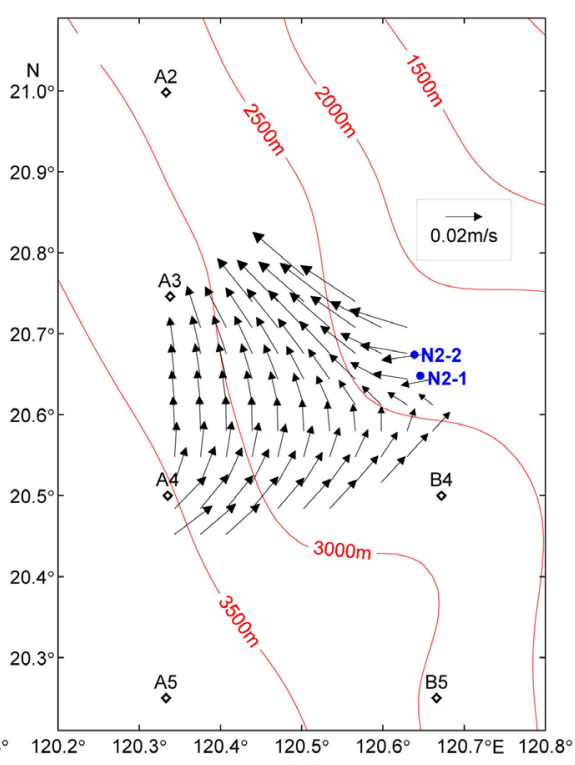

(d)

Figure 5. (a) The pressure anomaly $(\mathrm{kPa})$ distribution and (b) velocity vector $(\mathrm{cm} / \mathrm{s})$ at $1850 \mathrm{~m}$ in the Luzon Strait in July 2009. (c) and (d) are the same as (a) and (b), respectively, but at $1760 \mathrm{~m}$. Red lines: the water depths at isobaths. The reference level is based on $\mathrm{H}=2150$. 
flow nearly northeastward at about $20^{\circ} 30^{\prime} \mathrm{N}$ and then turn counterclockwise, flowing northwestward in the area $20^{\circ} 35^{\prime} \mathrm{N}$ to $20^{\circ} 45^{\prime} \mathrm{N}$. In other words, the current velocity vectors flow nearly along the isobaths. We compare the geostrophic current calculation with the direct observed current velocity at the depth of 1760 $\mathrm{m}$. At the depth of approximately $1760 \mathrm{~m}$ at station $\mathrm{N} 2-2$, the observed current velocity $(\mathrm{V}, \theta)=\left(2.2 \mathrm{~cm} / \mathrm{s}, 281.3^{\circ}\right)$ from July 7 to August 12,2009 ; the computed current velocity $(\mathrm{V}, \theta)=\left(3.0 \mathrm{~cm} / \mathrm{s}, 298^{\circ}\right)$ for a reference level $\mathrm{H}=2400 \mathrm{~m}$, and $(\mathrm{V}, \theta)=\left(3.0 \mathrm{~cm} / \mathrm{s}, 275^{\circ}\right)$ for $\mathrm{H}=2150 \mathrm{~m}$ in July 2009 . This suggests that: 1$)$ computed velocity vectors agree well with each other when the two different reference levels are used; and 2) regardless of the reference levels, the computed and observed results basically agree with each other. This shows that the estimated currents are similar if the reference level is changed to $\mathrm{H}=2150 \mathrm{~m}$ (see Figure 4 and Figure 5).

The above velocity vector distribution naturally can be explained from the pressure fields. From Figure 4(a) and Figure 4(c), the isopiestics also make counterclockwise turns from south to north. We further analyze the dynamical cause associated with each velocity component. 1) The v component: the pressure p on isopiestics (Figure 4(a) and Figure 4(c)) increases with longitude from west to east (i.e., the west-east pressure gradient is greater than zero, which results in the northward current velocity component from Equation (1), as shown in Figure 4(b) and Figure 4(d)). 2) The u component: Similarly, the south-north pressure gradient is also greater than zero, resulting in the westward current velocity component from Equation (2). Thus, the pressure anomaly field results in the above distribution of velocity fields at 1850 and $1760 \mathrm{~m}$ in Figure 4 and is also one of the dynamical causes.

Moreover, at the depth of $1850 \mathrm{~m}$ in July 2009, we compare the geostrophic current velocity station at N2-1 with that at station N2-2 to ensure data consistency between these two stations. The current velocity at station N2-1 is $(\mathrm{V}, \theta)=$ $\left(2.4 \mathrm{~cm} / \mathrm{s}, 308^{\circ}\right)$, and the current velocity at station $\mathrm{N} 2-2$ is $(\mathrm{V}, \theta)=(2.5 \mathrm{~cm} / \mathrm{s}$, $304^{\circ}$ ). This similarity suggests that these two locations are close to each other. Similarly, very similar current velocities can be found at $1760 \mathrm{~m}$ during the same observational period-current velocity $(\mathrm{V}, \theta)=\left(2.7 \mathrm{~cm} / \mathrm{s}, 303^{\circ}\right)$ at station $\mathrm{N} 2-1$ versus $(\mathrm{V}, \theta)=\left(3.0 \mathrm{~cm} / \mathrm{s}, 298^{\circ}\right)$ at station $\mathrm{N} 2-2$. These results support the combination of data from these mooring stations in the analysis.

Finally, we compare the geostrophic current calculation with the direct observed current velocity at the depth of $1760 \mathrm{~m}$. At this depth at station N2-2, the observed current velocity $(\mathrm{V}, \theta)=\left(2.2 \mathrm{~cm} / \mathrm{s}, 281.3^{\circ}\right)$ from July 7, 2009 to August 12,2009 , and the computed current velocity $(\mathrm{V}, \theta)=\left(3.0 \mathrm{~cm} / \mathrm{s}, 298^{\circ}\right)$ in July 2009. This shows that the computed and observed results basically agree with each other.

\section{Conclusions}

Based on the direct current measurements at mooring station N2-1 from October 2008 to January 2009 and at station N2-2 from July to August 2009, we 
present a very valuable dataset of deep current observations in the LS. The long period of observation (a total of $122 \mathrm{~d}$ from two separated cruises) is extremely unique. The hydrographic data obtained at station N2-2 from July 4 to 11, 2009 is also used to compute the velocity vector distribution at 1850 and $1760 \mathrm{~m}$ and verify the direct current measurements. Our results show a clear seasonal difference in the subtidal deep current velocity, $(\bar{u}, \bar{v})=(-2.8,1.6),(-3.5,1.2),(-0.4$, $0.2),(-0.9,0.7)$, and $(-2.2,0.4)$ (unit: $\mathrm{cm} / \mathrm{s}$ ) during the period from October 16 to 31; November and December, 2008; January 1 to 8, 2009; and July 7 to August 12, 2009, respectively. The current is strongest in autumn (October-November) and weaker in summer (July-August) and winter (December-January). The cyclonic and anti-cyclonic meander with different subtidal current directions plays an important role in the seasonal difference of the deep current in the LS. Comparing the observed current velocities in the DCWB of the northern Philippine Basin [19] with the observed deep current in the LS, we believe that the seasonal difference of the deep current in the LS is connected with the deep current at the DCWB of the northern Philippine Basin [19] and is also connected with the overflow near the central Bashi Channel and Luzon Trough [15].

The long dataset provides us an opportunity to further analyze the dominant periods associated with the deep current in the LS using the RWPSA. The zonal velocity has dominant periods of $8 \mathrm{~d}$ and $19 \mathrm{~d}$, and the meridional velocity has dominant periods of $8 \mathrm{~d}, 14 \mathrm{~d}$, and $28 \mathrm{~d}$. These periods with much weaker dimensionless PSD are consistent with the many dominant periods observed in the upper $300 \mathrm{~m}$ [16].

Furthermore, the geostrophic current calculation suggests that the deep currents flow nearly northward at about $20^{\circ} 30^{\prime} \mathrm{N}$ and then turn counterclockwise, flowing northwestward in the area $20^{\circ} 35^{\prime} \mathrm{N}$ to $20^{\circ} 45^{\prime} \mathrm{N}$. The currents are expected to flow nearly along the isobaths, for example, the current velocity vectors flow along the 3000-m isobaths toward the SCS. Thus, we conclude that the subtidal velocity distribution at 1850 and $1760 \mathrm{~m}$ results partially from the bottom topography effect.

The above velocity vector distribution can be naturally explained from the pressure fields. The positive west-east pressure gradient results in the northward current velocity, while the positive south-north pressure gradient results in the associated westward current. Thus, the dynamical cause of the resulting subtidal velocity distribution at 1850 and $1760 \mathrm{~m}$ is mainly due to the pressure field. Finally, the observed deep current also agrees well with the geostrophic current calculation, confirming that the strong geostrophic balance still holds for the deep current in the LS.

\section{Acknowledgements}

This study was supported by the National Key R \& D Program of China (2017YFC1404200), the National Program on Global Change and Air-Sea Interaction (GASI-IPOVAI-04), the China Ocean Mineral Resources Research and Development Association Program (DY135-E2-3-02), and the National Nature 
Science Foundation of China (41830540). It was also funded by the Project of State Key Laboratory of Satellite Ocean Environment Dynamics (SOEDZZ1802, SOEDZZ1803 and SOEDZZ1805).

\section{Conflicts of Interest}

The authors declare no conflicts of interest regarding the publication of this paper.

\section{References}

[1] Yuan, Y.C., Liao, G.H., Wang, H.Q. and Chen, R.Y.H. (2009) Variability of the Currents in the Luzon Strait during Spring of 2002 Obtained from Observations and Satellite Geostrophic Currents and Spectral Analyses. Science in China (Series D), 52, 519-531. https://doi.org/10.1007/s11430-009-0041-z

[2] Yuan, Y.C., Liao, G.H., Yang, C.H., Liu, Z.H., Chen, H. and Wang, Z.G. (2014) Summer Kuroshio Intrusion through the Luzon Strait Confirmed from Observations and a Diagnostic Model in Summer 2009. Progress in Oceanography, 121, 44-59. https://doi.org/10.1016/j.pocean.2013.10.003

[3] Fang, G.H., Wei, Z.X., Choi, B.H., Choi, K., Wang, Y.F. and Li, W. (2003) Interbasin Freshwater, Heat and Salt Transport through the Boundaries of the East and South China Seas from a Variable-Grid Global Ocean Circulation Model. Science in China (Series D), 46, 149-161. https://doi.org/10.1360/03yd9014

[4] Tseng, Y.H., Shen, M.L., Jan, S., Dietrich, D.E. and Chiang, C.P. (2012) Validation of the Kuroshio Current System in the Dual-Domain Pacific Ocean Model Framework. Progress in Oceanography, 105, 102-124. https://doi.org/10.1016/j.pocean.2012.04.003

[5] Metzger, E.J. and Hurlburt, H.E. (1996) Coupled Dynamics of the South China Sea, the Sulu Sea, and the Pacific Ocean. Journal of Geophysical Research-Ocean, 101, 12331-12352. https://doi.org/10.1029/95JC03861

[6] Cai, S.Q., Su, J.L., Gan, Z.J. and Liu, Q.Y. (2002) The Numerical Study of the South China Sea Upper Circulation Characteristics and Its Dynamic Mechanism in Winter. Continental Shelf Research, 22, 2247-2264. https://doi.org/10.1016/S0278-4343(02)00073-0

[7] Cai, S.Q., Liu, H.L., Li, W. and Long, X.M. (2005) Application of LICOM to the Numerical Study of the Water Exchange between the South China Sea and Its Adjacent Oceans. Acta Oceanologica Sinica, 24, 10-19.

[8] Fang, G.H., Wang, Y.G., Wei, Z.X., Qiao, F.L. and Hu, X.M. (2009) Interocean Circulation and Heat and Freshwater Budgets of the South China Sea Based on a Numerical Model. Dynamics of Atmospheres and Oceans, 47, 55-72. https://doi.org/10.1016/j.dynatmoce.2008.09.003

[9] Qu, T., Kim, Y.Y., Yaremchuk, M., Tozuka, T., Ishida, A. and Yamagata, T. (2004) Can Luzon Strait Transport Play a Role in Conveying the Impact of ENSO to the South China Sea? Journal of Climate, 17, 3644-3657. https://doi.org/10.1175/1520-0442(2004)017<3644:CLSTPA>2.0.CO;2

[10] Yuan, Y.C., Tseng, Y.-H., Yang, C.H., Liao, G.H., Chow, C.H., Liu, Z.H., Zhu, X.-H. and Chen, H. (2014b) Variation in the Kuroshio Intrusion: Modeling and Interpretation of Observations Collected around the Luzon Strait from July, 2009 to March, 2011. Journal of Geophysical Research: Oceans, 119, 3447-3463. https://doi.org/10.1002/2013JC009776 
[11] Yuan, Y.C., Liao, G.H., Guan, W.B., Wang, H.Q., Lou, R.Y. and Chen, H. (2008) The Circulation in the Upper and Middle Layers of the Luzon Strait during Spring 2002. Journal of Geophysical Research: Ocean, 113, C06004. https://doi.org/10.1029/2007JC004546

[12] Liu, C.-T. and Liu, R.-J. (1988) The Deep Current in the Bashi Channel. Acta Oceanography Taiwan, 20, 107-116.

[13] Qu, T., Girton, G. and Whitehead, J. (2006) Deepwater Overflow through Luzon Strait. Journal of Geophysical Research: Ocean, 111, C01002. https://doi.org/10.1029/2005JC003139

[14] Lan, J., Zhang, N.N. and Wang, Y. (2013) On the Dynamics of the South China Sea Deep Circulation. Journal of Geophysical Research: Ocean, 118, 1206-1210. https://doi.org/10.1002/jgrc.20104

[15] Zhou, C., Zhao, W., Tian, J., Yang, Q. and Qu, T. (2014) Variability of the Deep-Water Overflow in the Luzon Strait. Journal of Physical Oceanography, 44, 2972-2986. https://doi.org/10.1175/JPO-D-14-0113.1

[16] Yuan, Y.C., Yang, C.H., Tseng, Y.-H., Zhu, X.-H., Wang, H.Q. and Chen, H. (2017) Analysis of Longer Period Variation of the Kuroshio Current Intrusion into the Luzon Strait Using Rectified Wavelet Power Spectra. Progress in Oceanography, 156, 61-77. https://doi.org/10.1016/j.pocean.2017.04.013

[17] Tian, J., Yang, Q., Liang, X., Xie, L., Hu, D., Wang, F. and Qu, T. (2006) Observation of Luzon Strait Transport. Geophysical Research Letters, 33, L19607. https://doi.org/10.1029/2006GL026272

[18] Liu, Y.G., Liang, X.S. and Weisberg, R.H. (2007) Rectification of the Bias in the Wavelet Power Spectrum. Journal of Atmos and Ocean Technology, 24, 2093-2102. https://doi.org/10.1175/2007JTECHO511.1

[19] Zhou, C., Zhao, W., Tian, J.W., Yang, Q.X., Huang, X.D., Zhang, Z.W. and Qu, T.D. (2018) Observations of Deep Current at the Western Boundary of the Northern Philippine Basin. Scientific Reports, 8, Article No. 14334. https://doi.org/10.1038/s41598-018-32541-9

[20] Sarkisyan, A.S. (1977) The Diagnostic Calculations of a Large-Scale Oceanic Circulation. In: Goldberg, E.D., Mccave, I.N., O’Brien, J.J., et al., Eds., The Sea, Vol. 6, A Wiley-Interscience Publication, New York, 363-458. 